e0176473. 10.1371/journal.pone.0176473

4. Korhonen V, Soini $H$, Vasankari $T(2017)$, "Recurrent tuberculosis in Finland 1995-2013: a clinical and epidemiological cohort study", BMC Infect Dis. 2017 Nov 16;17(1):721. doi: 10.1186/s12879-017-2818.

5. Nguyễn Thi Phương Thảo (2008), "Nghiên cứu đặc điểm lẩm sàng, cận lâm sàng, tính kháng thuốc của vi khuẩn lao trong lao phổi tái phát".
Luận vă̆n Thạc sỹ, Học viện Quân y, Hà Nội 70tr.

6. Nguyễn Thị Hâu (2015), "Nghiên cứu lầm sàng, cận lâm sàng, tỷ lệ kháng thuốc và kết quả điêu trì tẩn công ở bệnh nhân lao phổi tái phát". Luận văn Thac sỹ, Hoc viên Quân y, Hà Nôi 67tr.

7. Jacobs MG, Pinto Junior VL(2020), "Characterization of drug-resistanttuberculosis in Brazil, 2014", Epidemiol Serv Saude. 2020 Feb 3;28(3):e2018294. doi: 10.5123/S1679.

\title{
ĐIỀU TRI THÀNH CÔNG BIẾN CHỨNG MÙ MẮT DO TIÊM CHẤT LÀM ĐẦY THẨM MỸ: TRƯỜNG HỢP ĐẦU TIÊN Ở' VIỆT NAM
}

\author{
Nguyễn Hồng Hà*, Trần Thị Thanh Huyền*, Dương Hồng Quân*, \\ Nguyễn Xuân Hiệp**, Nguyễn Quốc Anh**, Đồng Ngọc Minh* \\ Nguyễn Đình Minh*, Đào Xuân Hải*, Lê Thanh Dũng*
}

\section{TÓM TẮT}

Đă̆t vấn đề: Với sự gia tăng sử dụng chất làm đầy axit hyaluronic (HA) trong thẩm mỹ trên toàn thế giới, các biến chứng tắc mạch nghiêm trọngnhư mù mắt, liệt nửa người, hoại tử da ngày càng tăng. Nó có thể để lại các di chứng trầm trọng ảnh hưởng đến chức năng và thẩm mỹcủa bệnh nhân (BN). Theo y văn thế giới số ca cứu đước mốt phần thi lức từ chố mù hoàn toàn cũng chí có 2-3ca. Đối tượng và phương pháp: Chúng tôi báo cáo một trường hợp BN bị mất thị lực toàn bộ, thiếu máu da đe dọa hoại tử trán mũi, sụp mi ngay sau tiêm HA tạo hình mũi trái phép tại Spa. BN đã được điều trị cấp cứu tối khẩn cấp đa chuyên khoa, phối hợp đa phương thức cùng với can thiệp mạch, tiêm thuốc giải Hyaluronidase trực tiếp vào lòng đống mach mắt 2 lần. Kết quả: từ chố mất thị lực toàn bộ 2 lần, thị lực BN hồi phục đến 20/200, BN có thể đọc sách, điện thoai vàcũng có thể nhìn rõ đồ vật từ khoảng cách $5 \mathrm{~m}$. Kết luận: Qua ca bệnh thành công đâu tiên của Việt Nam chúng tôi nhận thấy mô hình đa phương thức, phối hợp đa chuyên khoa Tạo hình Thẩm mỹ, Mắt, Chẩn đoán hình ảnh, can thiệp mạch và Hồi sức có thể là giải pháp điều trị các biến chứng nghiêm trọng này một cách tối ưu nhất.

Tứ khóa: Biến chứng tiêm chất làm đầy; axit Hyaluronic; tiêm Hyaluronidase trong lòng động mạch; sự tắc mạch; động mạch mắt; thị lực

\section{SUMMARY \\ RECOVERY OF FILLER INDUCED TOTAL VISUAL LOSS: FIRST CASE OF VIETNAM AND LITERATURE REVIEW}

Introduction: With the global increase in the use ofinjectable hyaluronic acid (HA), more cases with

*Bệnh viện Hữu Nghi Việt Đức.

**Bênh viện Mắt Trung Ương.

Chịu trách nhiệm chính: Nguyễn Hồng Hà

Email: nhadr4@gmail.com

Ngày nhận bài: 2/12/2020

Ngày phản biên khoa hoc: 10/1/2021

Ngày duyệt bài $18 / 1 / 2021$ serious complication are being reported. HA embolism leads to serious complications including blindness, eye and eyelid movement disorders, skin necrosis and cerebral embolism. However, there is a lack of robust clinical evidence regarding recovery vision due to embolisme of ophthalmic artery and central retinal artery. Patient and method: We present a case report of a patient who developed features of vascular involvement after one $\mathrm{ml}$ of HA filler injection in the nasal dorsum illegaly at Spa. The patient initially developedsevere pain and total vision loss in the right eye immediately by the time of injection. Result: She was managed emergency with multiple disciplinary therapy combined of general and local treatment including ocular massage, hyaluronidase intracutanous, retrobulbar injections and intra arterial thrombolysis for 2 periods consecutive of vision loss. Significantrecovery in the vision and skin, ophthalmic components occurred within 6 weeks. Conclusion: This case demonstrates that recovery of the vision, ischaemic ophthalmic and cutaneous due to embolism of central retinal artery could be accomplished using combined multiple disciplinary therapy and intra arterial thrombolysis injections of hyaluronidase.

Keywords: Cosmetic injection complications; Dermal fillers; Hyaluronic acid; Intra-arterial thrombolysis; Embolism; Ophthalmic Artery ; Visual Acuity

\section{I. ĐĂT VẤN ĐỀ}

Trong những năm gần đây, việc tiêm axit hyaluronic (HA) để làm đẹp trên khuôn mặt đã trở thành thủ thuật thẩm mỹ phổ biến trên toàn thế giới do những ưu điểm của nó như: điều trị xâm lấn tối thiểu, chi phí thấp, ít đau với sư thành công cao trong việc tạo ra các kết quả bề ngoài ấn tượng $[1,2]$. Theo thống kê của Hiệp Hội Phẫu thuật Tạo hình Thẩm mỹ Thế giới (ISAPS) năm 2018 có khoảng 3,7 triệu ca tiêm chất làm đầy được thươ hiên bởi các bác sĩ Tao hình Thẩm mỹ [3]. Tî lệ các biến chứng tắc mạch gây thiếu máu và hoại tử tổ chức nói chung ước tính khoảng $3-9$ ca trên 10.000 ca tiêm [4]. Chưa kể 
do việc quản lý y tế không chặt chẽ nên ở nhiều nước các thủ thuật này có thể được thực hiện bởi các bác sĩ không chuyên khoa và thậm chí chỉ là những nhân viên Spa không hề có kiến thức về y khoa. Số lượng thủ thuật còn cao hơn nhiều và số lượng biến chứng cũng tăng lên gấp nhiều lần.

Hiện có nhiều phương pháp điều trị phối hợp như mát-xa nhãn cầu, tiêm thuốc giải hyaluronidase vào vùng da tổn thương, tiêm hậu nhãn cầu... Tuy nhiên cho đến nay các phươning pháp này hầu như chưa mang lại hiệu quả cho những $\mathrm{BN}$ mất thị lực toàn bộ sau tiêm do tắc ĐM mắt hay $Đ M$ trung tâm võng mạc $[1,5,6]$. Phương pháp tiêm trực tiếp thuốc giải và thuốc tiêu sợi huyết vào trong lòng động mạch còn nhiều tranh cãi giữa lợi ích và nguy cơ cững như sự phức tạp, nguy hiểm của kỹ thuật [7-8]. Trong y văn thế giới số ca cứu được một phần thị lực đếm trên đâu ngón tay còn số ca thông báo cứu được thị lực sau đó lại mất thị lực lần 2 rồi lại cứu được cũng chỉ có 2-3 ca [8].

\section{II. ĐỐI TƯợNG VÀ PHƯƠNG PHÁP NGHIÊN CỨU}

Bệnh nhân (BN) nữ 27 tuổi được tiêm $1 \mathrm{ml}$ chất làm đầy $H A$ nâng mũi trái phép tại Spakhoảng 19 h ngày 16/09/2020. Ngay trong lúc tiêm BN xuất hiện đau buốt dọc sống mũi lan vào tận não. Sau rút kim BN không nhìn thấy gì nữa. BN được chuyển cấp cứu đến BV Tỉnh thấy tiên lương rất xấu nên được chuyển về Bênh viện Việt Đức. BN đến viện khoảng $23 \mathrm{~h}$ trong tình trạng đau đớn, lo lắng, hoảng loạn, tím lạnh da vùng trán và sống mũi, mất toàn bộ thị lực mắt phải. Các bác sĩ (BS) Tao hình Thẩm mỹ đã phải kích hoạt quy trình cấp cứu khẩn cấp để chuẩn bị thuốc giải, mời BS chuyên khoa mắt, báo $B S$ hồi sức, mời $B S$ can thiệp mạch. Song song tiến hành mát xa nhãn câu, chỉ định thuốc giảm áp lực mắt. Xét nghiệm cơ bản không có dấu hiệu nguy cơ đe dọa đến tính mạng.Đến Oh35 ngày 17/09/20 BN được tiêm thuốc giải dưới da trán mũi và hậu nhãn cầu Hyaluronidase. Chụp động mạch (ĐM) số hóa xóa nền (DSA) cho thấy tắc toàn bộ ĐM trung tâm võng mạc là nhánh của ĐM mắt phải, võng mạc không thấy ngấm thuốc. Đưa microcatheter vào $Đ M$ mắt tiêm thuốc giải. Chụp kiểm tra thấy võng mạc ngấm thuốc. BN cải thiện thị lực rõ ràng, từ chố mất thị lực toàn bộ đển đếm được ngón tay $1 \mathrm{~m}$ rõ (gần như trước tai nạn).

Tình trạng thị lực ổn định đến 16h 17/09/20 BN lại xuất hiện mất thị lực lần hai và lại được tiêm thuốc giải hyaluronidasephối hợp thuốc tiểu sợi huyết trực tiếp vào lòng mạch để cứu lại được một phần thị lực.

\section{KẾT QUẢ NGHIÊN CỨU}

Sau 1 tuần $B N$ bớt sưng nề, bớt sụp $m i$, thị lực nhìn được đếm ngón tay $50 \mathrm{~cm}$, có vùng nhìn được có vùng không nhìn được, còn song thị. Sau 10 ngày Gối Aspegic $100 \mathrm{mg}$. Thay giảm đau đường uống. Thay kháng sinh đường uống Augmentin $1 \mathrm{~g}$, thuốc mắt vẩn duy trì tương tự.

Sau khoảng 2 tuần BN hết song thị, mắt vận động dễ dàng, phù nề kết mạc giác mạc giảm dần. Thị lực nhìn đc $1 \mathrm{~m}$ đếm ngón tay, nhận ra đồ vật. Sau 6 tuần điều trị BN được ra viện, thị lực Mắt $P$ 20/200, nhìn $5 \mathrm{~m}$ thấy được người và đồ vật. Đọc được chũ̃ trên hộp thuốc và đơn thuốc cũng như trên điện thoại và máy tính.

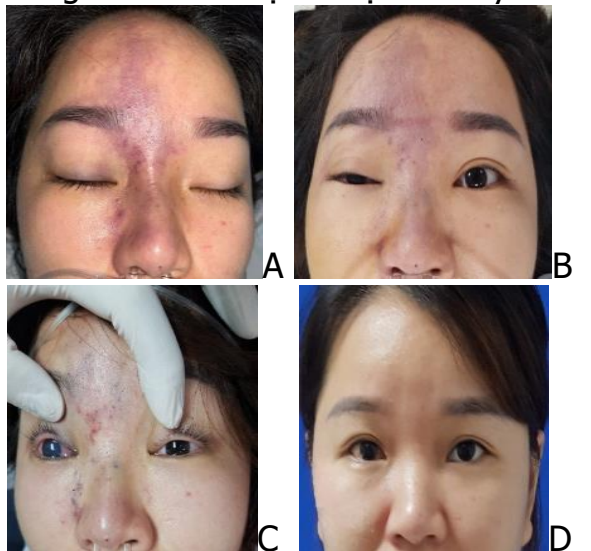

Hình 1. Biểu hiện lâm sàng của bệnh nhân

A. Lúc vào viện: mất thị lực toàn bộ, thị lực PXAS (-), da trán mũi tím lạnh

B. Sau tiêm Hyaluronidase thị lực cải thiện rõ rệt, đếm ngón tay rõ $1 \mathrm{~m}$, da đõ tím, vẫn sụp mi, hạn chế vận động nhãn cầu

C. Tắc mạch lần 2, đau, mất thị lực PXAS (-), phù giác mạc, phù kết mạc.

D. Tại thời điểm xuất viện, thị lực mắt Phải 20/200.

\section{BÀN LUÂN}

Trong các biến chứng của tiêm chất làm đầy thì biến chứng mù mắt, suy giảm thị lực hay đột quy là những biến chứng nặng nề và trầm trọng nhất $[1,4-8]$. Ở các nước không có sự quản lý chặt chẽ về y tế, các thủ thuật có thể được thực hiện một cách trái phép tại các spa bởi các nhẩn viển Spa nên con số tai biến nghiêm trọng ngày càng tăng và rất khó có sự thống kê chính xác. Đơn cử ở Việt Nam chỉ trong 3 năm từ 2018 đến 2020 đã có trên 10 ca có biến chứng mù mắt do tiêm chất làm đầyphải đưa đến cấp cứu ở các BV lớn và được các phương tiện thông tin đại chúng đưa tin. Có lẽ do không có ca nào hồi phục thị lực so với tình trạng lúc vào viện nên không có 
tác giả nào thông tin haybáo cáo trêntạp chí y học. Cho đến tháng 9 năm 2020 ca bệnh của chúng tôi là ca đầu tiên thành công trong việc giữ lại được thị lực cho BN được thông báo.

Trong nghiên cứu tổng quan y văn thế giới của Kapoor xuất bản tháng 12 năm 2019 về các biến chứng mất thị lực, mù mắt có liên quan đến tiêm HA làm đẹp cho thấy từ năm 2014 đến tháng 6 năm 2019 có tất cả 26 bài báo công bố về 44 trường hợp mù hoặc giảm thị lực. Hầu hết các trường hợp mù mắt do chất làm đầy $\mathrm{HA}$ được báo cáo từ Hàn quốc, thứ hai là Trung Quốc thứ 3 là Thái Lan, tiếp theo là từ Đài Loan, Hoa Kỳ... Mới đây vào tháng 1 năm 2020 trong báo cáo số ca lớn nhất của Trung quốc tác giả Zhang và $C S$ đã thông báo về $24 \mathrm{BN}$ bị tắc mạch sau khi tiêm HA thẩm mỹ mặt. Các tác giả đã kết hợp những phương pháp điều trị phối hợp với phương pháp tiêm trực tiếphyaluronidase vào trong động mạchthu được kết quả tốt [8].

Có nhiêu lý do gây ra biến chứng tắc mạch sau tiêm chất làm đầy $\mathrm{HA}$ và giả thuyết sự tắc mạch ngược dòng được chấp nhận rộng rãi. Trong quá trình tiêm, chất làm đầy có thể bị tiêm vào các ĐM quanh ổ mắt.Nếu áp lực tiêm cao hơn áp lực ĐM, dòng HA sẽ đi ngược vào trong so đến Đ̇ mắt, ĐM cảnh trong. Khi áp lực tiêm trở nên thấp hơn huyết áp, HA di chuyển xuôi theo dòng chảy đến các nhánh mạch: ĐM trung tâm võng mạc, ĐM mi sau, ĐM mi, ĐM não... gây tắc mạch với triệu chứng tương ứng $[1,5]$.

Nghiên cứu y văn của Kapoor cho thấy chỉ $0,2 \mathrm{ml} H A$ có thể gây ra mù vĩnh viễn toàn bộ, điêu này giả thiết rằng bản chất $\mathrm{HA}$ có thể là tác nhân kích thích quá trình gây tắc mạch. Tắc ĐM mắt và ĐM trung tâm võng mạc hay gặp nhất và tiếp theo là các nhánh của ĐM trung tâm võng mạc. Nếu chỉ tắc nhánh của ĐM trung tâm võng mạc thì tiên lượng tốt hơn, khả năng hồi phục cao hơn trong khi đó tắc ĐM mắt và ĐM trung tâm võng mạc có tiên lượng rất xấu, chỉ có $2-3$ ca hồi phục một phần thị lực $[1,5,6,8]$.

Thời gian vàng cho phép hồi phục khi tắc động mạch trung tâm võng mạc là 90 phút nên BN cần được chuyển đến các trung tâm chuyên khoa càng sớm càng tốt[5]. Khi nghi ngờ tắc mạch cần dừng tiêm ngay lập tức, tiến hành tiêm thuốc giải hyaluronidase, mát xa nhãn cầu và thở vào túi nylông để tăng nồng độ $\mathrm{CO} 2$ máu giúp giãn nở mạch máu trong quá trình vận chuyển[6].

Men giải hyaluronidase có thể làm tan các chất HA giúp thông mạch trở lại. Nhiều nghiên cứu chỉ ra rằng hyaluronidase có thể ngấm qua thành mạch máu mà không cần phải tiêm trực tiếp trong lòng mạch. Vì ĐM Mắt và ĐM trung tâm võng mạc lại đi vào trong vỏ bao của thần kinh thị nên thuốc giải ngấm qua một cách khó khăn vì vậy nhiều phương pháp tiêm thuốc giải với hiệu quả khác nhau còn đang được bàn cãi. Tiêm thuốc giải hậu nhãn cầu cũng là một sự lựa chọn. Thủ thuật này cũng đi kèm nguy cơ chấn thương nhãn cầu nên cần thực hiện bởi các bác sĩ chuyên khoa được huấn luyện [5].

Tiêm trực tiếp thuốc giải Hyaluronidase vào động mạch (intra arterial thromboysis, IAT) thông qua chụp động mạch số hóa xóa nền DSA được cho là một phương pháp hiệu quả để loại bỏ tắc mach. Một số nghiên cứu trước đây đã báo cáo tác dụng điều trị không đạt yêu cầu của phương pháp này đối với sự tắc mạch do $\mathrm{HA}$ [7,8], tuy nhiên đây chỉ là các nghiên cứu với cõ mâuu rất nhỏdẫn đến thái độ hoài nghi về các lợi ích của liệu pháp này. Trong nghiên cứu mới công bố gần đây của Zhang và CS, 42\% (10 trong số 24) BN có những cải thiện rõ ràng về thị lực sau liệu pháp này. Trường hợp $\mathrm{BN}$ của chúng tôi được tiến hành thủ thuật tiêm trực tiếp thuốc giải vào lòng $Đ M$ rất sớm, dưới $6 \mathrm{~h}$ từ lúc khởi phát. Kết quả chụp mạch trước can thiệp cho thây tắc hoàn toàn ĐM trung tâm võng mạc, võng mạc không được tưới máu tương đương với triệu chứng lâm sàng mất thị lực toàn bộ. Chì sau khi tiêm Hyaluronidase 1500UI, kêt quả chụp phim cho thấy võng mạc đã ngấm thuốc trở lại, trên lâm sàng $B N$ cải thiện thị lực rõ rệt. Trong lần tắc mạch thứ hai xảy ra sau đó 14 h nhờ có can thiệp thông tắc mạch, ngay sau tiêm Hyaluronidase phối hợp với thuốc tiêu sợi huyết chúng tôi đã thay đổi được tình trạng của người bệnh từ mất thị lực toàn bộ thành mất thị lực đến mức có thể đọc được chữ trên màn hình điện thoại hoặc máy tính. Qua kinh nghiệm rút ra từ ca bệnh này, chúng tôi nhận thấy tiêm trực tiếp thuốc giải thật sớm vào trong lòng $Đ M$ có thể sẽ là một lựa chọn cho biến chứng tắc mạchnghiêm trọng này.

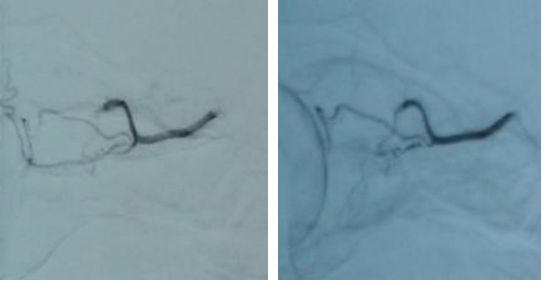

Hình 2.Chụp ĐM số hóa xóa nền trước và sau tiêm Hyaluronidase lần môt

Về khoảng thời gian giữa lúc xuất hiện biến chứng do tiêm HA đến khi được điều trị thực thụ 
nhất là được tiêm Hyaluronidase thông tắc mạch càng sớm thì khả năng tái thông mạch và sự cải thiện thị lực càng cao $[1,5,6]$. Tuy nhiên thực trạng hiện nay tại Việt Nam là hết sức đáng báo động. Khi xảy ra tai biến chứng do không có chuyên môn nên các trung tâm Spa cũng không biết chuyển $B N$ đến đâu để điều trị dẫn đến bỏ qua thời gian vàng. Chính vì vậy từ đâu năm 2020 các chuyên gia đầu ngành của các BV trung ương tại Hà nội đã thống nhất đưa ra quy trình phối hợp liên chuyên khoa, liên bệnh viện, tổ chức tiếp nhận thông tin và điều chuyển $B N$ đến trung tâm ngoai khoa có đủ các chuyên gia Phẫu thuật tạo hình Thẩm mỹ, Chẩn đoán hình ảnh can thiệp mạch, Gây mê hồi sức hiện đại, phối hợp với các chuyên gia Mắt, Tai mũi họng, Da liễu nếu cần.

\section{KẾT LUẬN}

Mất thị lực là một biến chứng hiếm gặp nhưng rất thảm khốc do tiêm chất làm đầy $\mathrm{HA}$ trong thẩm mỹ. Cho đến nay không có tiêu chuẩn vàng trong điều trị tắc ĐM mắt cũng như ĐM trung tâm võng mạc. Thành công từ $B N$ đầu tiên của Việt Nam cho thấy việc tổ chức các Đơn vị ứng cứu tai biến tiêm chất làm đầy $\mathrm{HA}$ chuyên sâu tại các Trung tâm Phẫu thuật Tạo hình Thẩm mỹ lớn, phối hợp đa chuyên khoa chẩn đoán hình ảnh, can thiệp mạch, mắt và hồi sức có thể điều trị các biến chứng nghiêm trọng này một cách tối ưu nhất.

\section{TÀI LIÊU THAM KHẢO}

1. Kapoor KM, Kapoor P, Heydenrych I, Bertossi D.Vision Loss Associated with Hyaluronic Acid Fillers: A Systematic Review of Literature. Aesthetic Plast Surg. 2020 Jun; 44(3): 929-944. Epub 2019 Dec 10.

2. Fallacara A, Manfredini S, Durini E, Vertuani S. Hyaluronic Acid Fillers in Soft Tissue Regeneration. Facial Plast Surg. 2017;33(1):87-96.

3. International Society of Aesthetic Plastic Surgeons (ISAPS) International survey on aesthetic cosmetic procedures performedin 2018 . ISAPS Global Survey Press Release. 3 Dec 2019

4. Beleznay $K$, Humphrey $S$, Carruthers JD, Carruthers A. Vascular compromise from soft tissue augmentation: experience with 12 cases and recommendations for optimal outcomes. J Clin Aesthet Dermatol. 2014; 7(9):37-43.

5. DeLorenzi C. Complications of injectable fillers, part 2: vascular complications. Aesthet Surg J. 2014; 34(4):584-600.

6. Thanasarnaksorn $W$, Cotofana $S$, Rudolph $C_{\text {, }}$ Kraisak P, Chanasumon $\mathbf{N}$, Suwanchinda A Severe vision loss caused by cosmetic filler augmentation: Case series with review of cause and therapy. J Cosmet Dermatol.J Cosmet Dermatol. 2018;17(5):712-8.

7. Chen YC, Wu HM, Chen SJ, Lee HJ, Lirng JF, Lin CJ, Chang FC, Luo CB, Guo WY. IntraArterial Thrombolytic Therapy Is Not a Therapeutic Option for Filler-Related Central Retinal Artery Occlusion. Facial Plast Surg. 2018 Jun;34(3):325-9.

8. Zhang LX, Lai LY, Zhou GW, Liang LM, Zhou YC, Bai XY, Dai Q, Yu YT, Tang WQ, Chen ML. Evaluation of Intraarterial Thrombolysis in Treatment of Cosmetic Facial Filler-Related Ophthalmic Artery Occlusion. Plast Reconstr Surg. 2020 Jan; 145(1):42e-50e.

\section{ĐÁNH GIÁ THỰC TRANG CÔNG TÁC CHUẨN BỊ NGƯờI BÊNNH TRƯớC MỔ CỦA ĐIỀU DƯỡNG CÁC KHOA THUỘC KHỐI NGOẠI BÊ̂NH VIÊ̂N ĐA KHOA TİNH SƠN LA NĂM 2017}

\section{TÓM TẮT}

Mục tiêu: Nhân xét thực trạng công tác chuẩn bị trước mổ cho người bênh (NB) mổ theo kế hoạch của Điều dưỡng các khoa thuộc khối Ngoại, Bệnh viện đa khoa (BVĐK) tỉnh Sơn La tại thời điểm nghiên cứu; đề xuất một số giải pháp nhằm nâng cao chất lượng

*Bệnh viện Đa khoa tỉnh Sơn La

**Trường Đai hoc Thành Đông

Chịu trách nhiệm chính: Phạm Thị Nhuyên

Email: nhuyenmd@yahoo.com.vn

Ngày nhận bài: 1/12/2020

Ngày phản biên khoa hoc: $5 / 1 / 2021$

Ngày duyệt băi: $25 / 1 / 2021$

\section{Tống Thị Minh Nhung*, Huỳnh Thị Bình*, Phạm Thị Nhuyên*, Đinh Ngọc Sỹ **}

chăm sóc người bệnh trước mổ tại BVĐK tỉnh Sơn La. Đối tượng và phương pháp: Nighiên cứu mô tả cắt ngang 451 NB có chỉ đinh mổ theo kế hoach, tại các khoa thuộc khối Ngoai-BVĐK tỉnh Sơn La; năm 2017. Kết quả và kết luẩn: Hầu hết các nội dung phải chuẩn bi cho NB trưởc mổ như: tiếp đón; hỏi bệnh; hướng dẫn làm xét nghiệm; vệ sinh các nhân trước mổ...[4,5] trong đó điêu dưỡng viên các khoa Ngoai đã chuẩn bi rất tốt $(100 \%)$, có 3 khoa thực hiên tồt là: Ngoại tổng hợp, Chấn thương, U bướu (82.5\%). Nôi dung điều dưỡng viên các khoa làm chưa tốt: Vê sinh, sát khuẩn vùng sẽ mổ. Đề xuất giải pháp: Bệnh viên cần thường xuyên kiểm tra, giám sát, đôn đốc thực hiện các quy định về chuẩn bị người NB nhiễm khuẩn; NB trước, trong và sau phẫu thuật. 